\title{
Glycaemic control influences heart rate responses to cardio-pulmonary exercise testing in type 1 diabetes
}

Othmar Moser, Olivia McCarthy, Rachel Deere, Max L Eckstein, Steve C Bain, Hanne L Haahr, Eric Zijlstra, Tim Heise, Richard M Bracken

\section{Background}

The myocardial response during CPX testing is thought to reflect a change in LVEF and allows for identification of a heart rate turn point (HRTP).

- In patients with type 1 diabetes both diastolic volume and LVEF fail to adequately increase during aerobic exercise compared with healthy individuals.

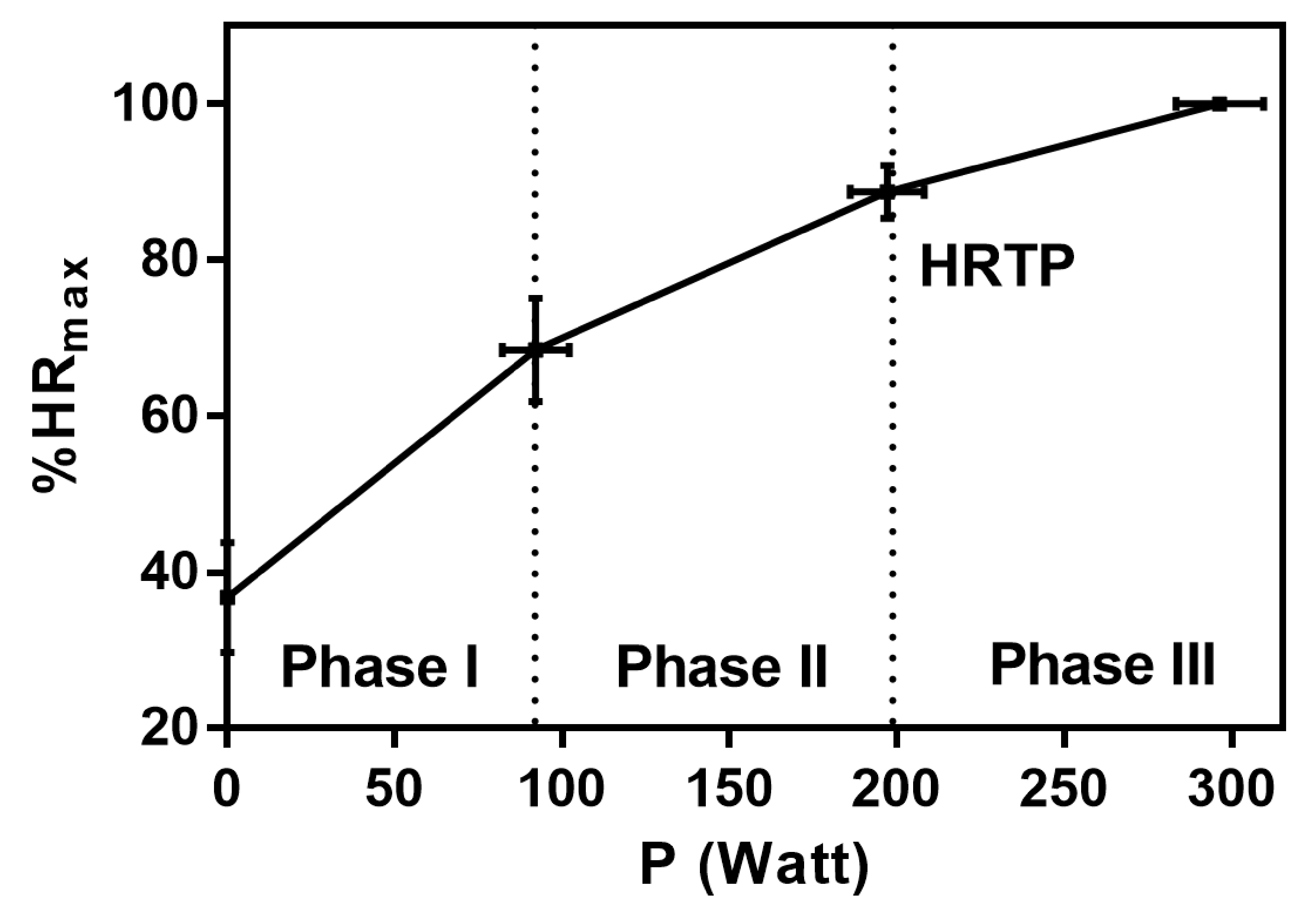

It is not known if the heart rate change in relation to exercise intensity is altered dependent on the glycaemic control in individuals with type 1 diabetes.

\section{Method}

\begin{tabular}{c|c|c|c|c|c}
$\mathbf{N}$ & $\begin{array}{c}\text { Age } \\
\text { (years) }\end{array}$ & Sex & $\begin{array}{c}\mathrm{HbA}_{1 \mathrm{c}} \\
\left(\%\left(\mathrm{mmol}_{\left.\cdot \mathrm{mol}^{-1}\right)}\right)\right.\end{array}$ & $\begin{array}{c}\mathrm{BMl} \\
\left(\mathrm{kg} / \mathrm{m}^{2}\right)\end{array}$ & $\begin{array}{c}\text { Diabetes } \\
\text { Duration } \\
\text { (years) }\end{array}$ \\
\hline 64 & $35 \pm 8$ & $13 f$ & $7.3 \pm 0.6(62 \pm 13)$ & $24 \pm 2$ & $15 \pm 9$
\end{tabular}

\section{Study protocol}

- Participants performed a CPX test until maximum • volitional exhaustion.

Relationships were examined between heart rate deflection and diabetes markers, anthropometry and exercise physiological markers and linear regression analysis was performed.
- ROC curves based on the slope of the increase in heart rate $\left(\mathrm{K}_{\mathrm{HR}}\right)$ for groups $\mathrm{k}_{\mathrm{HR}}<0.20$ vs. $>0.20$ in relation to $\mathrm{HbA}_{1 \mathrm{c}}$ and unpaired t-tests were performed with $P \leq 0.05$.

\section{Results}
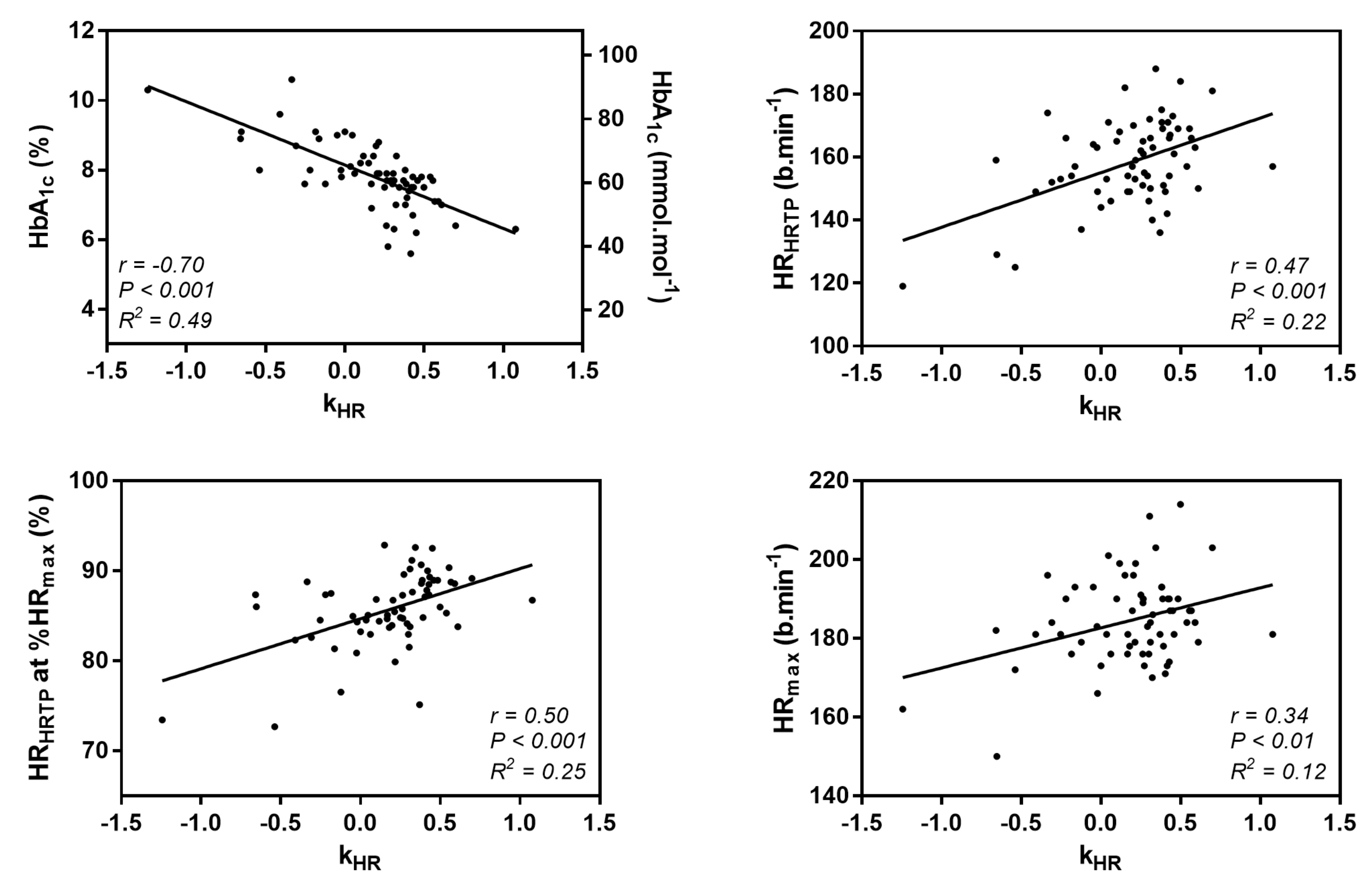

Relationships between slope of the increase in heart rate $\left(k_{H R}\right)$ and glycaemic control $\left(H b A_{1 c}\right)$, heart rate at the heart rate turn point ( $\left.H R_{H R T P}\right)$, heart rate at the heart rate turn point given as percentage of maximum heart rate $\left(H R_{H R T P}\right.$ at $\left.\% H R_{\text {max }}\right)$ and maximum heart rate $\left(H R_{\max }\right)$.
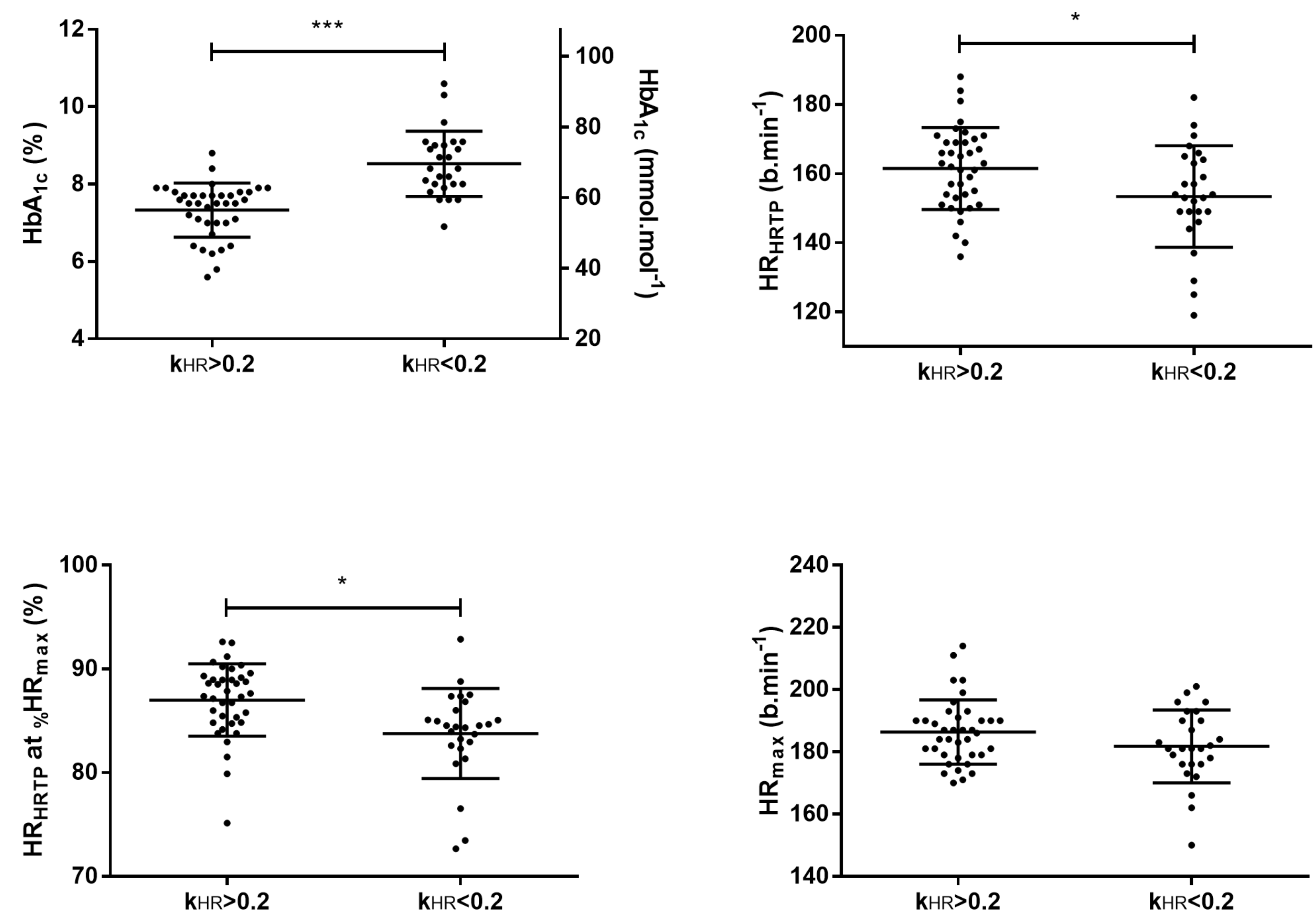

Grouped data based on slope of the increase in heart rate $\left(k_{H R}\right)$ for glycaemic control $\left(H b A_{1 c}\right)$, heart rate at heart rate turn point $\left(H R_{H R T P}\right)$, heart rate at heart rate turn point given as percentage of maximum heart rate $\left(H R_{H R T P}\right.$ at $\left.\% H R_{\text {max }}\right)$ and maximum heart rate $\left(H R_{\text {max }}\right)$.

ROC curve analysis resulted in a $\mathrm{HbA}_{1 \mathrm{c}}$ threshold of $7.9 \%$ (81\% sensitivity, $82 \%$ specificity).

\section{Discussion}

Our data suggest caution in applying physical training recommendations based on heart rate in patients with poor glycaemic control. 